\title{
Camelia Elias
}

\section{- Wit as Final Aesthetic Imperative - The fragmentary aNd THE INCOMPLETE IN SCHLegel, BLANCHOT, AND JABÈS}

The future is faced with fragments, with fragments of an impossible future, a future that itself appears fragmentary. And this is the best, and for no reason. - Simon Critchley

Aphoristic language is pre-digested speech: between thinking and speaking is the silence of wit.

What makes aphoristic language characteristic of the Romantic period is its dealing with the co-existence of contraries, which then resulted in formulating a poetics for the difference between the unity of opposites and the coincidence of opposites. The first marks a constant, whereas the latter is a variable of modality. While the unity of opposites goes by an archaic formula for wholeness to express a symbol of perfection, autonomy, strength (Schlegel), the coincidence of opposites most often expresses a paradox that leads to fragmentation and nostalgia, (Blanchot and Jabès) - both of which, however, are Romantic traits par excellence. Mircea Eliade, for instance, has developed the idea that God can only be grasped as coincidentia oppositorum, as a paradox that goes beyond comprehension. ${ }^{1}$ The mystery one is left with can be deciphered only via the apprehension of the unity of opposites as a symbolic reference to God.

On the other hand, there are other ways of expressing this difference as did Wittgenstein when he claimed that "whereof one cannot speak thereof one must be silent", while Stanislaw Jerzy Lec gave it an epigrammatic twist: "In the beginning was the Word. Silence was created later". "Whereof" as the

1 Mircea Eliade, Myten Om Den Evige Genkomst, (København: MunksgaaardRosinante, 1966).

2 Stanislaw J. Lec, More Unkempt Tboughts, (New York: Funk \& Wagnalls, 1968), 53. 
unity of opposites reverses the "thereof" as the coincidence of opposites, which results in a discourse on the idea of wit as the final imperative of the ineluctable in any conclusion. Thus neither nostalgia nor the co-existence of contraries reflects any "final" difference or analysis. Not in the sense that the difference is that there is no difference, but in the sense that between a constant and a modal there is the idea, as the "forever becoming". In Bataille's words, the copula, "the verb to be is the vehicle of amorous frenzy". S Schlegel's aesthetics was his concern with wit, Blanchot's with "writing" wit, and Jabès's with "wasting" wit.

The objective of this paper is to investigate the notion of wit, first as a hermeneutic imperative that constitutes the frame of the romantic text, and second, as an aesthetic imperative which further frames the romantic form of wit able to represent itself as text - as a romantic text par excellence. As Schlegel heralds, wit resides not so much in romantic poetry, as it finds its locus in the process of "forever becoming", in the fragment that folds and refolds poetry to produce writing that approaches infinity. Via insights from the quest for the literary absolute formulated by Philippe Lacoue-Labarthe and Jean-Luc Nancy, this paper attempts to answer the following question: what kind of an identity does the fragment assume, if one follows the hypothesis that the core of the romantic idea is inherent in the question of how one poetically interprets interpretation as an end in itself? A dialectical reversal of theorizing on the fragment (Schlegel) into theorizing the fragment fragmentarily (Blanchot), lies at the heart of romantic writing in its dealing with wit as a system, social feeling, and architectonic form that probes the totality of the fragment. I argue that the romantic fragment eludes the polarity between completeness and incompleteness and culminates in a hermeneutics of radicality.

\section{The Schlegelian fRagment Par EXCellence}

Following the Romantic assumption that the literary yields to the absolute, in the sense that the literary is made irreducible to conceptuality, it can be said that the fragment by definition becomes an aesthetic imperative: one can aim at the fragment's endless transformations around a complete form, but can never achieve it. I shall further argue that the fragment's completeness, or incom-

3 Georges Bataille, Visions of Excess - Selected Writings, 1927-1939 (Minneapolis: University of Minnesota Press, 1985), 5. 
pleteness realizes itself in an aesthetic process of forever becoming centred on the question of authenticity as the counter-point of wit. The interpretation of, or response to the fragment can be said to be inherent in the idea of not ever being able to grasp its completeness, hence what the fragment exhibits is a call for the interpretation of an aesthetic ideal: the fragment as agent, as an open work of art is never completed, but always targets a correspondence with what is transcendent, elective, mandatory.

An example of what links the literary qualities of a theory on the fragment to theorizing fragmentarily is the tripartite relation of reading as writing as interpretation. If, as Edmond Jabès contends, "words elect the poet", articulates the question of reading rather than writing, it can be argued that wit mediates between whom the words choose to elect and finally finds itself grounded in a similar dictum: fragments mandate the poet. Schlegel's theory of the fragment is in this sense a constant figuration of the question "why write in fragments" before a definition of the fragment is ever stated. Questioning the question, as it were, prompts thinking in the direction of listening as a genre in itself more or less established in the poetics of Edmond Jabès. As Mark C. Taylor remarks in his foreword to The Book of Margins, "Jabès's texts recount stories that are not stories and events that are not events. They tell us notbing". ${ }^{5}$ Maurice Blanchot sees this notbing as that which interrupts discourse in order to make communication possible, claiming that "the gap makes becoming possible". 6

Although this paper will not engage with the poetic discourse of Jabès as such, it is interesting to note that the question of expressing "nothing" also seems to have been the core of Schlegel's figuring and refiguring of wit as a means of writing and rewriting the difference that "nothing" as an exigency or an imperative poses. Unlike Jabès, for whom the relation writing/silence is resolved in the relation writing/nothing, Schlegel swings his pendulum-pen between writing/wit and writing/nothing-but. Ever engaged in a dialogue "but only with those who are à la bauteur", Schlegel posits the question of form as the identity of the fragment to be found, defined, and refined in its own totality:

${ }^{4}$ Edmond Jabès, $A$ Share of Ink, (London: Menard Press, 1979), 30.

5 Mark C. Taylor, "Series Editor's Foreword" in Edmond Jabès, The Book of Margins (Chicago: The University of Chicago Press ,1993), x.

6 Maurice Blanchot, "Interruptions" in Eric Gould, ed., The Sin of the Book: Edmond fabès (Lincoln \& London: University of Nebraska Press, 1985), 44. 
A: You say that fragments are the real form of universal philosophy. The form is irrelevant. But what can such fragments do and be for the greatest and most serious concern of humanity, for the perfection of knowledge?

B: Nothing but a Lessingean salt against spiritual sloth, [...] marginal glosses to the text of the age. ${ }^{7}$

On the question of form as a marginal gloss, it can be contended that inasmuch as form is the condition of the possibility of presenting the fragment, it cannot itself be properly represented, and is in this sense irrelevant. If the margin delineates the moment separated from present reference, if the margin is made up of signs that refer only to something not actually present in it, then what the margin contains is the space of nothing, the text of the age, as the age of the sign, in Schlegel's own contention, nothing but Lessingean salt. The irrelevance of the form then, inscribes itself within an economy of representation. Blanchot writes that in Jabès's work the container is the contained, as it were, the economy of representation thus referring to the "totality" of the container that accomplishes itself in the act of containing itself. ${ }^{8}$

In other words, margins mark the completion of the fragment as a result of more than one "imperative". It is on the ground of the margin that the fragment's literariness can only be aimed at, and in the context of aesthetic understanding it is thus linked to what Andrew Bowie calls "the hermeneutic imperative", which he posits vis-à-vis Novalis's "aesthetic imperative" that defines the ideality inherent in works of art - the work of art being for Bowie the element that "always poses new interpretive tasks". 9

Now, the position of the fragment as represented in the early German romantic period is dominated by the idea of "progress", which makes it possible for the romantic writers to mark completion as subsequent to the philosophical programme expressed. In this way, the romantic philosophical programme is not a just a programme, as much as it is aesthetics. And what would have to be emphasized here is the difference between these two modes, where the aesthetic experience is identified with both theory and art. Of course, philoso-

7 Friedrich Schlegel, Pbilosopbical Fragments (Minnesota: University of Minnesota Press, 1991), 54-55.

8 Maurice Blanchot, "Interruptions" in Eric Gould, ed., The Sin of the Book: Edmond Fabès (Lincoln \& London: University of Nebraska Press, 1985), 48.

${ }^{9}$ Andrew Bowie, From Romanticism to Critical Theory - The Philosophy of Literary Theory (London \& New York: Routledge, 1997), 88-89. 
phical aesthetics is constitutive of the "Idea", ${ }^{10}$ which for the German romantics is poetry, in the sense that it primarily and exclusively includes an opposition to every unwarranted juxtaposition with other areas, meaning, that which is not the domain of literature or philosophy. What constitutes this other domain can be gauged from Friedrich Schlegel's fragment 116 on "Universal Transcendental Poetry" of the Athenaeum fragments, in which it becomes apparent how this constitution is devoid of definition in the strict sense, relying on the affirmation of its own specificity:

Romantic poetry is a progressive universal poetry. It is destined not merely to reunite the separate genres of poetry and to link poetry to philosophy and thetoric. It would and should also mingle and fuse poetry and prose, genius and criticism, artistic poetry and natural poetry, make poetry lively and sociable, and life and society poetic, poetise wit, fill and saturate the forms of art with worthy cultural matter of every kind, and animate them with a flow of humour. ${ }^{11}$

Progressivity is thus seen as a constitutive value with the property to link genres across different aesthetic practices, romantic poetry being a matter of fate. It is interesting that romantic poetry is seen, or rather "destined", as mediator: Schlegel describes the Romantic progressive poetry as that which reunites separate genres. But this call for an actualization of the integration of philosophy into poetry can be said to raise the question of the application of the theory that is in a constant process of becoming. Says Schlegel further in the same fragment:

Among the arts Romantic poetry is what wit is to philosophy, and what sociability, friendship and love are to life. Other types of poetry are complete and can now be wholly analysed. Romantic poetry is still in the

10 I follow here also the description - with its hinted at ambiguity posed in the question "but what is an idea?" - rather than the definition of the "idea" as given in The Literary Absolute, where the authors make reference to the last part - entitled Ideas - of the collection of fragments published by Schlegel and his Jena friends (A. Schlegel, Tieck, Wackenroder, Novalis) between 1798-1800 as The Atbenaeum Fragments. They write: "Of course, as in the case of the fragment, no definition exists. While the history of fragmentation undeniably moves toward a certain deepening, it is not at all certain that it proceeds in the sense of a clarification: In fact, besides a very vague (but very 'profound') proposition near the beginining of the collection ("Ideas are infinite, autonomous, continuously moving in themselves, divine thoughts", I 10) and a reminder in extremis, of the function of the 'idea', no formal determination whatsoever of the thing ever appears. [...] Certainly, it was no small task to locate a suitable substitute for "Fragment"." Philippe Lacoue-Labarthe \& Jean-Luc Nancy, The Literary Absolute: The Theory of Literature in German Romanticism (Albany: SUNY Press, 1988), 63.

${ }^{11}$ Friedrich Schlegel in Lilian R. Furst, European Romanticism - Self definition, (Lincoln \& London: Methuen Press, 1980), 4. 
process of becoming; this indeed is its very essence, that it is eternally evolving, never completed. It cannot be exhausted by any theory, and only a divinatory criticism could dare to try to characterise its ideal. It alone is infinite, just as it alone is free, recognising as its prime law that the poet's caprice brooks no law. Romantic poetry is the only type of poetry that is more than merely a type of poetry; it is in fact the very art of poetry itself: for in a certain sense all poetry is or should be romantic. ${ }^{12}$

Here we have a clear case of poetry being seen as an evolving romantic theory: romanticism seeks to synthesize universality and particularity to create an organic work of art. In this sense, successive ideas on imagination, when united, each reflects the conditions under which it functions. In so far as there is an identification of what wit is to philosophy, by the same token it can be inferred that it is what imagination is to poetry. Ernst Behler also argues that this manifestation as a basic reflection "eludes any final formulation and does not result in an ultimate doctrine". ${ }^{13}$

Thus, for Schlegel, romantic aestheticism is given in deciding between viewpoints that ultimately ought to reveal unity in diversity. In romantic poetry unity transcends diversity in such a way that unity, and not as an ideal as it was for the Greeks, gives space to the process of becoming; the state of poetry becomes an endless process. While classical art stresses particularity and denies universality, romantic poetry stresses a moment of transition from being more than merely a type of poetry to being the very art of poetry itself.

It is at this transitional point that Blanchot's own "the gap makes becoming possible" intersects with Schlegel's discourse on the importance of thought exchange for the production of romantic poetry, in itself aiming to be infinite. Discoursing on the ambiguity inherent in defining the infinite is what Schlegel, Jabès and Blanchot have in common. Schlegel calls it dialogue, Jabès calls it desert, and Blanchot calls it disaster. Writing the three instances informs the aesthetics of the interruption, as the nothing, which is also characteristic of a transitional point that generates imperatives. The demand of writing in fragments itself serves as an original or authentic text. Via poetic interpretation the demand of writing settles in the aim for transformation: from the full text to the fragment whose point of view expresses a coherent whole.

12 Ibid., 5.

${ }^{13}$ Ernst Behler, German Romantic Literary Theory (Cambridge: Cambridge University Press, 1993), 8. 
That poetic interpretation of interpretation does not need to seek truth or origin, as it is an end in itself, is similar to Behler's description of Romantic theory: "the early Romantic theory can be described as an interaction of the literary and the philosophical encyclopaedias - not as their synthesis, to be sure, but as an attempt to think philosophy from the point of view of poetry and poetry from the point of view of philosophy."14

Schlegel's theory of romantic poetry is, however, circular for how is one to understand the concept of becoming if it relates to the manifestations of the subject's "will to system"? Now, one must speculate why Schlegel is so concerned with the "system". (Here it should be noted that Schlegel uses the idea of system interchangeably: there is a philosophical system, a fragmentary system, and a romantic system, and all three are interrelated.) One assumption is that the system possesses immediacy - the system repeats what you see, inwardly that is, with the eyes of your witz. One's witz also possesses immediacy, it takes one's imagination to the limits. As Schlegel put it in the Athenaeum fragment 383:

There is a kind of wit [witz] which, because of its solidity, thoroughness, and symmetry, one is tempted to call architectonic wit. Expressed satirically, it produces the only real sarcasms. It has to be properly systematic, and then again, it doesn't; with all its completeness, something should still seem to be missing, as if torn away. ${ }^{15}$

Clearly, Schlegel favours wit to best represent what the system marks as its difference: the non-system, the "then again" not systematic, although the difference is not in content but in representation. In other words, can wit replace the system? This question is what concerns Schlegel when he decides (almost in deconstructive overtones): there is no system - romantic system or otherwise as soon as the system is invoked, it becomes annulled by a number of hypothetical formulations, such as, not yet(s), as if(s), and as yet(s). This is in effect what confers on wit its architectonic form. Behler notes that scepticism and the belief in the pursuit and realisation of a final goal is maintained simultaneously in the romantic conception with the purpose of perfecting the infinite becoming which validates the fragmentary mode. He writes:

Schlegel justifies fragmentary writing "as long as" we have not yet established the completed system of knowledge, and he demands irony "wher-

${ }^{14}$ Tbid., 8.

15 Friedrich Schlegel, Pbilosopbical Fragments (Minnesota: University of Minnesota Press, 1991), 78. 
ever philosophy appears in oral or written dialogues - and is not simply confined to rigid systems." In a similar sense, philosophy is in need of "genial inspirations" and "products of wit" as long as it is not yet entirely systematic. 16

The infinite becoming, then, can be said to be on the verge of the "margin of nothing" as a means of creating the "provisional philosophy" which Schlegel sees constituted "before drafting a logical constitution", ${ }^{17}$ before the margin runs off to frame another non-system.

\section{WIT - IN AND OUT OF PERSPECTIVE}

If romantic poetry is fragmentary by self-definition, then the fragment as such expresses wit as external, which means that wit functions as an interposed text to the extent that it subordinates itself to the pragmatic character of romantic poetry: the poem's structure is to be commented upon more accurately by describing the function of the fragmentary. In this sense irony expresses itself in a self-referential context which goes beyond its problematic, from the form to the framework where the question of arbitrariness becomes a question of metainquiry. The pragmatism can be justified in one of Schlegel's formulations that has a double character: "In poetry too every whole can be a part and every part really a whole." 18 Wit too, as a pragmatic form, manifests itself in parodying every convention that wit as an imaginative form or "fragmentary genius" finds worthy of exploitation, where exploitation means play.

A similar idea is expressed in The Literary Absolute, where the double-sidedness of witz is presented as the principle of unity between fragments. But since wit functions as a principle, the first assumption would be that it must reside in the ininer form of the fragment. However, here the authors identify a paradox as they point out: "it was never really possible to assimilate $W i t z$ to a genre or a work", 19 which means that witz really resides in the outer form of the fragment. On the one hand, it is evident that this is the social aspect of wit,

${ }^{16}$ Ernst Behler, German Romantic Literary Theory (Cambridge: Cambridge University Press, 1993), 71.

17 Friedrich Schlegel, Pbilosopbical Fragments (Minnesota: University of Minnesota Press, 1991), 55.

18 Ibid., 2.

19 Philippe Lacoue-Labarthe \& Jean-Luc Nancy, The Literary Absolute: The Theory of Literature in German Romanticism, (Albany: SUNY Press, 1988), 54 
which Schlegel refers to in fragment 9 of the "Critical Fragments": "Wit is absolute social feeling, or fragmentary genius." 20 On the other hand, witz, which is outside the form that accomodates it, seeks a formal law that moves away from forms of sociality. "Fragmentary genius" then, must refer to the aesthetic effect that witz confers on writing, as Schlegel puts it in fragment 394: "It's a great mistake to try to restrict wit to society [...] It's just that real wit is still conceivable only in written form, like laws". ${ }^{21}$

Nevertheless, inasmuch as witz moves circularly (cf. fragment 113: "A classification is a definition that contains a system of definitions"22), we must agree with Lacoue-Labarthe and Nancy that it constitutes a "dialectical $A$ ufbebung", an up and down movement dislocated from an aesthetic concern with formal values per se. The "internal antinomy of Witz" is also given in what I would call the reverse of the double side of wit, which ultimately is not double at all, but a reverse that is already received in the form of a "not-yet-system". A further example of this metalepsis can be found in Lacoue-Labarthe's and Nancy's proposition: "The absolute idea of the Work, it is also the not-evenwork that must still be made to work", and in their claim that "Fragmentary geniality' preserves $W_{i t z}$ as work and suppresses it as non-work, sub-work, or anti-work. Which implies, it seems, that geniality also forms the Aufbebung of the voluntary and the involuntary".23

Thus, it seems that wit not only has a double side, a reverse side, an outside, and an inside, but also a counter-side which completes the architectonic shape of wit in its own deconstruction. Moreover, this counter-side marks the impossible centre where the fragment is fixated, still. This situation is rendered possible by plurality. For instance, Lacoue-Labarthe and Nancy argue that "to write the fragment is to write fragments", thus anticipating the "futuricity' of the project to catch up with the centre always half-ways, for, to write fragments means to "reduce" the text. And then they counter-argue:

But this plural is the specific mode in which the fragment aims at, indicates, and in a certain manner posits the singular of its totality. Up to a certain point, the formula employed by Friedrich Schlegel for the Ideas may be applied to all the Fragments: each one "indicates the center" (I

20 Friedrich Schlegel, Pbilosopbical Fragments (Minnesota: University of Minnesota Press, 1991), 2.

21 Ibid., 80.

22 Tbid., 31.

23 Philippe Lacoue-Labarthe \& Jean-Luc Nancy, The Literary Absolute: The Theory of Literature in German Romanticism (Albany: SUNY Press, 1988), 54. 
155). Yet neither of the concepts used here belongs to the space of the Fragments themselves, for it is not exactly "indicating" a "center" that is in question in the Fragments (...) Each fragment stands for itself and for that from which it has been detached. Totality is the fragment itself in its completed individuality. It is thus identically the plural totality of fragments, which does not make up a whole (...) but replicates the whole, the fragmentary itself, in each fragment. ${ }^{24}$

The structure of seeing the centre as a mode that inhabits plurality is thus fundamental on at least two accounts. First, to the identification of the fragment as the fragment that indeed replicates itself, and second, to the experience of the fragment, because it forms the basis for the way in which the reader has the potential to grasp precisely its aesthetics.

Timothy Clark offers a different perspective of totality as the fragment, and suggests that it is a response to the transformations of the concept of incompletion inherent in the fragment to move beyond itself whereby it would be completed. In this sense, the form of the fragment "sets the reader to work", and the totality of the work is seen as a limit that is "neither transgressed, nor affirmed; it is transformed". ${ }^{25}$ Clark's argument is that a fragment's identity marks a direction governed by internal criteria that determine the fragment's entrance in a circuit of abstract and formal system of descriptions, although, as he infers, this is still content based. That the fragment has an identity at all is more a matter of circumstance than deliberation which would incorporate the imaginative. Writes Clark:

The identity of each fragment is not determined in itself nor does it find determination in the ensemble of fragments toward which it delivers itself. It maintains a singularity that both exceeds and resists subsumption in the network of fragments, yet by the same token this singularity falls short of a determined identity and constitutes a lack in any putative totality. 26

This is to say that the determination of the fragment's indeterminative identity can only be anchored in the idea of transformation, which is almost the same as Schlegel's own "forever becoming": the step beyond mere philosophy is the step towards the more sophisticated form of philosophy already exemplified in

${ }^{24}$ Ibid., 44.

25 Timothy Clark, "Modern Transformation of German Romanticism: Blanchot and Derrida on the Fragment, the Aphorism and the Architectural" in Paragraph - A Fournal of Modern Critical Theory, vol. 15, no. 3 (Oxford: Oxford University Press, 1992), 237.

$26 \mathrm{Ibid}$ 
the dialogue: "A. You say that fragments are the real form of universal philosophy. The form is irrelevant". In other words, the real form of philosophy is a provisional form, yet bound to be all-inclusive in its constitution. Thus, the identity of the fragment is both given in its totality as well as in the transcendence of the subject. Again, as Schlegel's "B" replies: "[...] marginal glosses to the text of the age."

Now, Clark places the Schlegelian fragment against Blanchot's criticism of the romantic fragment as such. Clark is interested in the fragment as the aphorism, where the aphorism is the architecture which attempts to methodologically answer the question of form and fragmentation in Blanchot and Derrida. On this account the two positions counter-point each other in the same desire of expression that goes beyond "calculation". Blanchot's own fragmentary writing in The Writing of the Disaster determines the identity of the fragment as an exigency for self-commentary, while Schlegel's fragmentary writing is based on exigency for philosophical investigation. There is however a difference: Blanchot's practice institutes a series of fragments that go beyond the limit that fragments constitute, although this enterprise takes place only as a transformation "of the topology or space of writing itself", ${ }^{27}$ as Clark puts it. In contrast, I would suggest that Schlegel's practice pivots on a determination of the topology of writing the wit.

Moreover, the transcendence of the subject works as a fulfilment of the demand for the "unexistence" of the subject: Schlegel achieves it by means of irony, Blanchot by means of unworking the irony. In other words, wit is for Schlegel what writing is for Blanchot. Where wit for Schlegel enforces a space for the fragment as a representation of form, writing enforces for Blanchot a representation of the form of representation. Where Schlegel can be read to be transforming the aesthetic representation by advocating a philology of history as well as a historical poetics of philosophy - as a reaction to Kant - Blanchot can be said to be revising this same aesthetic representation, turning it into an act of cancelling itself out by "unworking" the conditions of its own possibility. This act of 'unworking' takes place at the junction where "literature encounters its most dangerous meaning - that of interrogating itself in a declarative mode". 28 Consequently, literature is also determinative of its own mode of

27 Tbid.

${ }^{28}$ Maurice Blanchot, The Infinite Conversation (Minnesota: University of Minnesota Press, 1993), 354. 
expression, which further justifies, to a certain extent, Blanchot's claim that the main objective of romantic literary expression is "to be everything but without content". ${ }^{29}$ Clark puts it in a nutshell:

The literaty form, for Schlegel, affirms itself as its self-transcendence in irony or criticism. Nevertheless, there is the most minute yet decisive difference between this affirmation of the work as transcending its finitude by ironic acknowledgement of it and Blanchot's notion of a work's inherent completion: [...] the more a work comments upon itself, the more it calls for commentaries. Blanchot's fragments acquire an oddly repetitive quality that yet never exhausts the reader's sense of novelty and strangeness. While Schlegel's fragments affirm an excess to any finite determination, Blanchot's, as they move through a series of related meditations upon what he terms "the neuter", "the anonymous", "the nameless", and "the fragmentary exigency", generate themselves out of the attempt to let speak a lack whose insistence intensifies in proportion to the writing that might seem to complement or fill it. This is the fragmentary exigency, the demand of/in writing, "beyond" or "behind" any subjective desire of expression or any conscious calculation. ${ }^{30}$

If one were to take "the subjective desire of expression" one step further, one would have to decide about one's own position as a reader. But this position seems to give itself in advance. The idea that there is a difference between understanding and not understanding the text further generates the desire to dispense with the rules, if there are any rules, and thus "imagine" the meaning of the text (still), if it has a meaning. Further, this position posits the question: is the comprehension of the text as a whole exterior to the incorporation of what is different in the text within the reader's systematic work?

Here, I can refer to the essay "A Portrait of Interpretation" by Ruth Lorand who distinguishes interpretation - its objectives, its specificity, its logical status and its objects - from other cognitive activities, such as describing, explaining, clarifying, decoding, which, she argues, each aims at answering a different question. Before the reader engages in the different interpretive stages rendered by Lorand, the reader has to first "recognize the problem". The assumption is that there are conceptual differences between description and interpretation and evaluation and interpretation. What interests us here are the

29 Ibid., 353.

${ }^{30}$ Timothy Clark, "Modern Transformation of German Romanticism: Blanchot and Derrida on the Fragment, the Aphorism and the Architectural" in Paragrapb - A Fournal of Modern Critical Theory, vol. 15, no. 3 (Oxford: Oxford University Press, 1992), 237. 
claims she makes in connection with when and how an interpretation is in order based on the dichotomy between completeness/incompleteness:

We interpret when we wish to complete what is apparently incomplete (or disordered). We interpret when we believe in the genuine coherence of the object and wish to demonstrate this coherence by struggling with difficulties on its "surface" [...] The conviction that an object is genuinely incomplete in some crucial sense forms the basis for criticizing the object and exposing its deficiencies. [...] Criticism attacks and distorts the object's apparent completeness, while interpretation aims at dissolving apparent incompleteness [...] Any object which appears incomplete, but is believed to contain the potential for its own completeness, calls for interpretation 31

If interpretation follows wishes and beliefs, interpretation would then manifest itself in its very potential to be an entity as it appears to the conceptual frame of concepts. Ergo, interpretation is romantic by virtue of integrating completeness where there is none. The crux of Schlegel's theory is that wit carries interpretation beyond the analytical construction of meaning. As wit no longer is a category but a condition, wit becomes romantic hermeneutics. Interpretation is thus the geist of the fragment.

\section{CONCLUDING REMARKS}

In sum, there is one legitimisation for fragmentary exigency, and that is given in the question of authenticity as the counter-point of wit, for the question prompts itself - as if with Schlegelian resonance - who is the author of wit? As I have tried to point out, wit marks a difference, not in the content of the fragment but in the way the fragment is represented, as a representation with different functions, such as the aphorism. The writing of wit, then, within the frame of the fragment's representation, can be said to work as a performance of the process of writing itself.

In effect, Schlegel's theory of the fragment continues the line of thought - in a metaleptic way - of such poets as Blanchot and Jabès, for whom totality as the fragment is directly linked to yet another function of the counter-side of wit, which is the margin of the "nothing". It is on this threshold that it is possi-

31 Ruth Lorand, "A Portrait of Interpretation" in $A E$, vol. 2, 1998, 10-11 http://tornade.ere.umontreal.ca/ guedon/AE/vol_2/lorand.html. 
ble to claim plurality for the writing of the fragment as fragments. The writing of nothing becomes the radical hermeneutics of the aesthetic fragment. Thus the fragment is functional: its incompleteness marks the totality or the wholeness of another fragment. I recall here Lacoue-Labarthe and Nancy's declarative statement: "to write the fragment is to write fragments".

In this way, the hermeneutic imperative alongside the aesthetic imperative are both dependent on the plurality of the fragment, on the fragment's incompleteness as a "forever becoming whole". Wit is, on the one hand, external to the system of the fragment, and thus wit is social feeling, and internal to the "not-yet-system" of the fragment, and thus wit is architectonic. The system of the fragment marks here what Schlegel calls "real wit" which is "conceivable only in written form". "No wit" as distinguishable from "real wit", is perhaps a form of "pseudo-wit" as "nothing but wit".

It is then only fair to assume that Schlegel's own share of ink splashes in such a way that it creates affinities with whomever the capricious words choose to elect. 